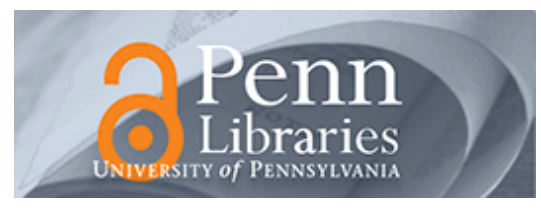

University of Pennsylvania

ScholarlyCommons

Marketing Papers

Wharton Faculty Research

2017

\title{
Multi-Attribute Loss Aversion and Reference Dependence: Evidence from the Performing Arts Industry
}

\author{
Necati Tereyağoğlu \\ Peter S. Fader \\ University of Pennsylvania \\ Senthil K. Veeraraghavan \\ University of Pennsylvania
}

Follow this and additional works at: https://repository.upenn.edu/marketing_papers

Part of the Advertising and Promotion Management Commons, Applied Behavior Analysis Commons, Behavioral Economics Commons, Business Administration, Management, and Operations Commons, Business Intelligence Commons, Cognition and Perception Commons, Cognitive Psychology Commons, and the Marketing Commons

\section{Recommended Citation}

Tereyağoğlu, N., Fader, P. S., \& Veeraraghavan, S. K. (2017). Multi-Attribute Loss Aversion and Reference Dependence: Evidence from the Performing Arts Industry. Management Science, 64 (1), 421-436.

http://dx.doi.org/10.1287/mnsc.2016.2605

This paper is posted at ScholarlyCommons. https://repository.upenn.edu/marketing_papers/384

For more information, please contact repository@pobox.upenn.edu. 


\title{
Multi-Attribute Loss Aversion and Reference Dependence: Evidence from the Performing Arts Industry
}

\author{
Abstract \\ We study the prevalence of multiattribute loss aversion and reference effects in a revenue management \\ setting based on data of individual-level purchases over a series of concert performances. The reference \\ dependence that drives consumer choice is not only based on the price but also on observed sales (as a \\ fraction of the seating capacity) during their past visits. We find that consumers suffer from loss aversion \\ on both prices and seats sold: consumers incur significant utility loss when prices are above their \\ references or when the actual seat sales are lower than their references. We suggest pricing policies that \\ can address consumer decisions driven by such reference dependence and loss aversion.

\section{Keywords} \\ multiattribute reference dependence, loss aversion, capacity-reference levels, empirical operations \\ management, marketing

\section{Disciplines} \\ Advertising and Promotion Management | Applied Behavior Analysis | Behavioral Economics | Business | \\ Business Administration, Management, and Operations | Business Intelligence | Cognition and Perception \\ | Cognitive Psychology | Marketing
}




\title{
Multi-attribute Loss Aversion and Reference Dependence: Evidence from the Performing Arts Industry*
}

\author{
Necati Tereyağoğlu \\ Scheller College of Business, Georgia Institute of Technology, Atlanta, Georgia 30308, \\ necati.tereyagoglu@scheller.gatech.edu \\ Peter S. Fader, Senthil Veeraraghavan \\ The Wharton School, University of Pennsylvania, Philadelphia, Pennsylvania 19104, \\ faderp@wharton.upenn.edu, senthilv@wharton.upenn.edu
}

May 2015

\begin{abstract}
We study the prevalence of endogenously driven multi-attribute reference effects in a revenue management setting based on data of individual level purchases over a series of concert performances. The reference dependence that drives consumer choice is not only based on the price but also on observed sales (as a fraction of the seating capacity). We show that consumers set their own internal price and sales reference levels through observations during their past visits. We find that consumers also suffer from loss aversion on both prices and seats sold: consumers incur significant utility loss when prices are above their references or when the actual seat sales are lower than their references. We provide insights into pricing policies that can address consumer decisions driven by multi-attribute reference dependence and loss aversion. We show it may be better to discount prices for sections with high sales than sections with low sales particularly for concerts with relatively low sales. Overall event popularity dampens loss aversion on seat sales, but reference-dependent behavior persists.

Keywords: Multi-attribute Reference Dependence, Loss Aversion, Sales-Reference Levels, Empirical Operations Management, Marketing.
\end{abstract}

${ }^{*}$ The authors thank the performing arts organization for providing the data necessary to conduct this research. They sincerely acknowledge the Fishman-Davidson Center for Service and Operations Management, the Wharton School, University of Pennsylvania for their support for this research. The authors thank the seminar participants at the 2013 INFORMS Annual Meeting in Minneapolis, the 2014 POMS Annual Conference in Atlanta, and the Wharton Workshop on Empirical Research in Operations Management 2014. 


\section{Introduction}

Consider the following scenario. An orchestra wants to provide discounts to boost the sales for the remaining concerts in the season. People can often observe prices and attendance for all seating zones in the concert hall prior to their purchases and because they regularly attend concerts, they may remember the prices and sales for all past concerts they attended. In this situation, as a manager, would you consider discounting the seating zones that are not performing well? On the one hand, people would experience additional gain from the discounted seat prices and would be more likely to purchase tickets from that zone. On the other hand, if the increase in sales does not exceed anyone's references, they would not feel the pressure to purchase the tickets, and would be less likely to purchase tickets from that zone.

In revenue management settings, such as hotel rooms, travel packages, shows, or musical events, products or services have multiple attributes that define the overall consumer experience. In such industries, regularly attending consumers' decisions can be driven by their references to past experiences, norms or status quo. Under such reference-dependent preferences, consumer decisions could be driven by comparisons to a reference point, instead of being driven directly by the utility consumed from the good.

Analyzing reference-dependent preferences has gained the wide-spread attention of behavioral researchers in economics and recently in operations and marketing settings. Innately, such reference dependence leads to a bifurcation of outcomes into either a gain or a loss with respect to the reference point. In addition, consumers may weigh losses more heavily than gains in their decisions, a notion described as loss aversion which is an important tenet of prospect theory (Kahneman and Tversky 1979). Using a theoretical setup, Popescu and Wu (2007) shows the operational implications of reference dependence and loss aversion on firm's price decisions. We enrich this research stream by documenting the empirical evidence for reference dependence and loss aversion in a particular revenue management setting.

The main goal of this paper is to empirically evaluate reference dependence and the presence of loss aversion driven by reference driven preferences using consumer level data of repeat purchases. Our customer-level data allows us to study repeated choice decisions of customers when they observe prices and sales from multiple alternatives (different seat zones) throughout the selling horizon 
(season). In such repeat-purchase settings, it is natural to expect that consumers, using their past consumption experience, often form reference points on multiple attributes of the product. Following prospect theory, customers may weigh losses stronger than gains (relative to the reference points) not just for a single attribute but also for multiple attributes (Tversky and Kahneman 1991) in their choices.

To this end, we use a multi-attribute reference-dependent choice framework (Tversky and Kahneman 1991) to model a consumer's seating area choice decisions. We develop and estimate a price-sales references model, and use the price and sales references predicted from this model as a reference point for each alternative. Then, we explore whether seating area choice is influenced by the position of seating zones relative to the price and sales references, and whether consumers weigh losses from references more than equivalent sized gains. For calibration of this two-step model, we use customer-level transaction data for three seasons of concerts from one of the leading symphony orchestras in the United States.

We show that the effect of referencing is strong and the consumers are loss averse across multiple attributes that have been the focal interest of operations management research, namely prices and capacity sold. Surely, researchers in operations and marketing have examined price reference effects in isolation. However, it is also important to evaluate the reference effects on sales, given the observations of consumer preferences based on sales. For instance, as pointed out by the social proof literature, customers may prefer seeing the event from crowded sections since seeing the actions of other people has an important effect on an individual's behavior (see Cialdini and Goldstein 2004, Cialdini 2007, Nodder 2013, and Zaki 2013 for more on social proof, and Becker 1991 for more on social influence). In fact, it is not known how sales reference effects interacts with price reference effects. For instance, if the price of a ticket is higher than a consumer's reference, he incurs negative utility or loss, leading him to skip buying a ticket, or avoid choosing a seat from that seating zone. On the other hand, if the attendance exceeds a consumer's reference, he may be inclined to buy the tickets (gain), which may outweigh the loss from prices, and he may still purchase a seat.

To explore the implications of price and sales reference dependence and loss aversion on the organization's pricing decisions, we use our calibrations to run some counterfactual pricing experiments. We find that the organization may improve revenues by offering discounts for sections with higher sales than those with lower sales. 


\section{$1.1 \quad$ Literature Positioning}

Our paper contributes to documentation of reference effects, which have been a focal area of interest in behavioral economics and marketing, and recently in operations management.

Reference effects have shown to cause behavioral anomalies in a variety of field settings - in shopping grocery items (Hardie et al. 1993), housing decisions (Genesove and Mayer 2001), game show contestant behavior (Post et al. 2008), insurance choice (Barseghyan et al. 2011), and sports (Pope and Schweitzer 2011). For more details on applied work, see DellaVigna (2009). Nevertheless, the application of reference dependence in revenue management settings is understudied, despite the expectation that consumers in such experience good markets are likely to engage in referencedependent purchases.

Some of the recent behavioral literature has also focused on the nature of reference point formation, which creates a primary challenge for field testing reference dependence. In some cases, a status quo, a well-defined numerical threshold, or a goal might act as reference points (see Camerer et al. 1997, Hossain and List 2012, and Allen et al. 2013). However, in a theater-like setting, performances have idiosyncratic values for customers, and these values may change based on their past experiences. Thus, determining reference points poses some challenges. Our approach on determining the reference points is based on updating memories on past experiences at the individual level (by exploiting the repeat purchase data available at the individual level). As such, our approach is consistent with reference dependence based on expectations (Köszegi and Rabin 2006) and past experiences (Post et al. 2008).

As prospect theory posits, consumers may also weigh losses (with respect to the reference point) heavier than they weigh gains (Kahneman and Tversky 1979). Researchers in marketing have further examined the reference price formation process and its effect on purchases, such as coffee brands and sizes (Kalwani et al. 1990, Lattin and Bucklin 1989, and Winer 1986). Much of this research on asymmetry in consumer responses to losses versus gains has focused on a single attribute - typically loss aversion analysis on prices (Kopalle et al. 1996, and Fibich et al. 2003). For an exception, Hardie et al. (1993) examines multi-attribute reference points in line with Tversky and Kahneman (1991). We also examine multi-attribute reference points (price and seat sales). However, in contrast to the extant research, one of our attributes - observed seat sales - is endoge- 
nously influenced by the other attribute (price). We are not aware of any other paper analyzing endogenously influenced multi-attribute reference levels.

We add to this stream by allowing consumers to form their multi-attribute reference levels on prices and sales based on each other rather than treating the formation of these reference points independently. In line with the previous stream of research, consumers still use their memories on prices and sales to form their references. Moreover, consumers also use information from external factors such as remaining time to the show, performance day and seating zone related factors to form their reference levels.

Almost all of the recent interest in operations management on price-reference effects in the context of revenue management is theoretical, beginning with Popescu and Wu (2007) who examine price reference on a single product. Nasiry and Popescu (2011) extend the results to complex memory-based reference price models. Similar reference framing has been modeled in various operational settings, focusing on a single attribute, such as service levels (Aflaki and Popescu 2014), past delay experiences (Yang et al. 2014a), social comparisons of performances (Roels and Su 2014), and future expected payoffs (Liu and Shum 2013). In contrast, we focus on the interaction between loss aversion in multiple attributes (namely, price and observed sales). Yang et al. (2014b) consider loss aversion in multiple attributes, such as price and waiting times, in a queuing setting where reference points for both attributes are exogenously given. In contrast, reference points for multiple attributes in our setting are jointly determined by consumers based on their past experiences. Our research goal is to provide support to theory on multi-attribute reference dependence and loss aversion, and fill the gap in empirical evidence on both directions.

Finally, our work is peripherally related to the research on positive externalities. For example, an increased sales expectation can improve utility for consumers due to social conformity (Becker 1991), herd behavior (Bikhchandani et al. 1992), queue information (Veeraraghavan and Debo 2009), network effects (Katz and Shapiro 1985), or market frenzies (DeGraba 1995). Similarly, the literature on social proof suggests that witnessing the actions of other people has an important effect on an individual's behavior (see Cialdini and Goldstein 2004, Cialdini 2007, and Nodder 2013 for a review). Observed queue length may signal quality to less informed consumers before they decide to buy the product (Debo et al. 2012). In such cases, the sales information will affect a firm's future pricing decisions (see Amaldoss and Jain 2005a, 2005b, and Debo et al. 2012). 
Given the paucity of data on customer references, and the difficulty in identifying the correct reference levels for endogenously-generated multiple attributes of the product, very little research has been conducted to evaluate the existence of loss aversion on both price and sales. To this end, we develop a joint price and sales references model that accounts for the endogeneity between the two key attributes during the reference formation process. This helps us to identify multi-attribute reference dependence and loss aversion. We compare the degrees of loss aversion on prices and sales of seating zones. Finally, using the reference-dependent choice model, we provide policy implications for the firm on how to price the seat zones differently over a season, and also how the prices of different seat zones interact among themselves and with the event-level effects.

We find that it may be better to offer ticket discounts in sections with high sales (than those with lower sales) to improve revenue. This observation is due to the interaction between loss aversion and multi-attribute reference dependence. Furthermore, the effect of loss aversion is more pronounced for concerts with lower overall sales. Gains due to the reference dependence along multiple-thresholds act as positive feedback when seats sold as a fraction of capacity are high; when sales are low, any gains due to price discounts are insufficient to overcome the loss in sales attributes.

\section{Problem Context and Methodology}

Revenue management $(\mathrm{RM})$ for arts and theaters is a complex problem that involves several price decisions that are prone to consumer behavior, which is highly susceptible to event experience. Despite the recent growth of the theoretical pricing and revenue management literature (see Leslie 2004, Rosen and Rosenfield 1997, and Talluri and van Ryzin 2004), the effect of loss aversion in such settings has not been explored. In this study, we focus on two factors that influence consumer reference-dependent purchasing behavior: their price and sales anticipations. We do this in the context of data from an orchestra on repeat purchases of single tickets.

Consumers who attend shows on a regular basis, are likely to use their experiences to build reference points for their future purchasing decisions. For instance, they may see gains from discounted zone prices and losses from increased zone prices (compared to their reference points). Hence, the often-seen reticence to dynamic pricing could be understood through loss aversion. Due 
to loss aversion and reference dependence, a consumer who sees a sequence of $(\$ 10, \$ 15, \$ 10)$ might incur more losses despite paying less than a consumer who sees $(\$ 12, \$ 12, \$ 12)$. Our study and conclusions also strengthen such observations.

Consumers may also use the information on number of seats sold as a fraction of capacity or availability, which they observe prior to their purchases, as reference points, in addition to price reference points. In theaters and stadiums, seats have idiosyncratic value to each person depending on the type of the show, seat position, and customer characteristics (Veeraraghavan and Vaidyanathan 2012). At every purchase, customers observe how many others buy in different seat categories. Under these circumstances, consumers may also use seat sales for each category as a reference point. If the sales observed at the time of next purchase is below that reference point, the consumer may experience some disutility.

Roadmap of our Methodology. The context that we examine is one in which consumers make purchases over a series of concerts at different prices and different seating zones. We first construct a reference-dependent utility and choice in Section 2.1. We calibrate the gains and losses with respect to those price and seats-sold reference levels in Section 2.2.

Recall that price drives sales and therefore will also drive sales reference levels at the consumer level (e.g., a consumer may have anticipate higher sales for a low-priced seating zone). Since sales observations are also referenced, they affect future purchases at any price (e.g., a consumer may not buy ticket in a zone where no one has yet purchased a ticket). Hence, we have to model a framework for joint price and sales reference formation process, which we develop in Section 2.3. To this end, we build a system of simultaneous equations that update price and sales references as dependent variables and as co-factors of each other (see Greene 2011 for more details).

At this juncture, we point out that (i) there is endogeneity between price and sales reference points, and (ii) these reference points held in consumer minds are not observable. We solve the identification issue by using pre-determined variables that come from past customer experiences as instrumental variables (done in Section 2.4). To address unobservability of reference points, we model the errors made by customers in anticipation of actual prices and sales with a formulation that dates back to Zellner et al. (1966), which we use to set the multi-attribute individual reference points following Kalwani et al. (1990) and Kőszegi and Rabin (2006) (done in Section 2.5). Hence, 
our approach stays consistent with recent economic thought on formation of reference-thresholds, while also helping us address the limitations in secondary data (since transaction data typically does not capture information on consumer-level references).

\subsection{Reference-Dependent Utility and Choice}

We are interested in the pre-consumption value of an event as perceived by customers before their attendance and construction of a utility dependence on reference points. We use a linear specification for the link between the reference-dependent utility of the customers and the potential influencing factors. Let $v_{i j t}$ be the (deterministic component of the) utility that customer $i$ derives by purchasing a ticket from the performance day-zone alternative $j$ (product type $j$ ) for concert $t$. We propose ${ }^{1}$

$$
v_{i j t}=\beta_{0 j}+\beta_{1} Z L_{i j t}+\beta_{2} D L_{i j t}+\beta_{3} P G A I N_{i j t}+\beta_{4} P L O S S_{i j t}+\beta_{5} S G A I N_{i j t}+\beta_{6} S L O S S_{i j t},
$$

where $\beta_{0 j}$ is a seating zone-specific factor (which may capture some zone-specific factor not addressed by other factors). PGAIN $N_{i j t}$ and $P L O S S_{i j t}$ capture the utility gain and loss (respectively) felt by customer $i$ with respect to his or her reference threshold on price at alternative $j$ for concert $t$. Similarly, $S G A I N_{i j t}$ and $S L O S S_{i j t}$ characterize the utility gain and loss incurred on the deviation from the reference on the fraction of seats sold in alternative $j$ for customer $i$ at concert t. Finally, Guadagni and Little (1983) demonstrates the importance of capturing prior loyalty to account for the dynamic nature of the purchase incidence feedback process in repetitive purchase settings. In a similar vein, we use customer loyalty toward seating zone $Z L_{i j t}$, and the day of performance $D L_{i j t}$ of concert $t$ to avoid biased coefficient estimates for price and observed sales constructs. $^{2}$

\footnotetext{
${ }^{1}$ In the marketing literature, a stream of papers (Lattin and Bucklin 1989, Kalwani et al. 1990, Mayhew and Winer 1992, and Kalyanaram and Little 1994), following the sticker shock model introduced by Winer (1986), also include separate price levels in the reference-dependent utility model. In this case, the multi-attribute utility would be formulated by including the price and sales levels separately in equation (1). We test and find the loss aversion and reference dependence on price and sales variables persist under the sticker shock modeling framework in subsection 4.5.1. We follow Tversky and Kahneman's (1991) framework which focuses on the relative difference between the attribute and the reference level in formulation of our choice model throughout the paper.

${ }^{2}$ In marketing, there is ongoing research on building better constructs of loyalty (see Aggarwal 2004, Gustafsson et al. 2005, and Johnson et al. 2006). To maintain the research focus, we use a generally accepted construct for loyalty measures as an exponentially weighted average of the past choices of zones and performance days. Specifically, we express zone loyalty as $Z L_{i j t}=\delta_{z} Z L_{i j t-1}+\left(1-\delta_{z}\right) \mathbb{1}_{i j t-1}^{z}$ and day loyalty as $D L_{i j t}=\delta_{d} D L_{i j t-1}+\left(1-\delta_{d}\right) \mathbb{1}_{i j t-1}^{d}$, where $\delta_{z}$ and $\delta_{d}$ are the carryover constants, and $\mathbb{1}_{i j t-1}^{z}$ and $\mathbb{1}_{i j t-1}^{d}$ are indicator variables that give 1 if customer $i$
} 
Some concert halls offer a purchasing feature through their website with a default option to view the "the best seat available at any zone". Depending on how this feature is programmed, some zones and days may be coded as preferable to other zones and days. In our case, the customer can purchase tickets through the website, phone or the ticket counter at the orchestra venue. In all channels, the customers can check occupancy levels and the prices for different seating zones. On the web-site or at the counter, the customer can choose an option similar to "the best seat available at any zone". We include $Z L_{i j t}$ and $D L_{i j t}$ to account for any seating zone or performance day related internal or external factors (e.g., website features) which may cause customers to gravitate towards purchases from one particular seating zone and/or performance day.

If there is a reference dependence on price, the coefficient of the gain variable PGAIN, $\beta_{3}$, should be positive while that of the loss variable PLOSS, $\beta_{4}$, is expected to be negative. Similar observations would hold for gains and losses on seats sold, i.e., the coefficient of $S G A I N, \beta_{5}$, is expected to be positive while the coefficient of $S L O S S, \beta_{6}$, is expected to be negative. Following the results of loss aversion, we also expect customers to have asymmetric responses to gains relative to losses on price and seat sales, for each alternative.

Reference-Dependent Choice Model. Since there are multiple alternatives, each with reference dependent utilities, we can use the multinomial logit model (McFadden 1974) with reference dependent utilities to model the choice between the alternatives. We use a linear-in-parameter functional form to represent customer $i$ 's utility for the purchase of choice alternative $j$ for concert $t$ as $U_{i j t}=v_{i j t}+\xi_{i j t}$, where $v_{i j t}$ is the deterministic component of utility as in equation 1 , and $\xi_{i j t}$ refers to random unobserved errors. If we assume that the error terms, $\xi_{i j t}$, for the different choice alternatives are independent and identically distributed with a Gumbel type II extreme value distribution, then customer $i$ 's choice probability for alternative $j$ is shown by McFadden (1974) to be

$$
\mathbb{P}_{i j t}=e^{v_{i j t}} / \sum_{\forall k \in J} e^{v_{i k t}},
$$

purchased from the seat zone and performance day of alternative $j$, respectively, at purchase occasion $t-1$, and 0 otherwise. 
which is the well-known multinomial logit formulation. ${ }^{3}$ In the following sections, we detail how the individual reference-dependent utilities $v_{i j t}$ are formulated.

\subsection{Reference-Dependent Gains and Losses}

Let $P_{i j t}$ be the price of the ticket for the alternative $j$ observed by customer $i$ at purchase instance $t$. Similarly, let $S_{i j t}$ be the fraction of the capacity sold for alternative $j$ observed by customer $i$ at purchase instance $t$ (i.e., $S_{i j t}=0.5$ means the $50 \%$ of the seats in that day-zone alternative $j$ of concert $t$ have been sold).

To address the reference-dependent gains and losses, we directly employ the reference-dependent functional form (additive, decomposable reference structure, and constant loss aversion) characterized in Tversky and Kahneman (1991) on prices and seats sold into consumer's utility. ${ }^{4}$ In particular, a customer experiences a gain from the price attribute of an alternative when the observed price for that alternative is less than his reference price for the alternative. A gain leads to a higher likelihood of a ticket purchase from that alternative. Similarly, a customer experiences a loss when the observed price is higher than his reference price. The reference point for each customer can be different based on differences in their interactions with the organization in the past. We simply use $R P_{i j t}$ as the notation for the reference price for an alternative $j$ for customer $i$ at purchase instance $t$.

Price Gain and Loss. For calibration purposes after the calculation of price reference levels, we calculate $P G A I N_{i j t}$ and $P L O S S_{i j t}$ using the $\log$ transformations of the reference and observed prices. First, we formulate the price reference effect $\left(R_{\text {Price }}().\right)$ in line with Tversky and Kahneman

\footnotetext{
${ }^{3}$ We allow the choice set to include the outside option since some consumers may not attend a show. The drawback of this decision is not observing the prices and sales for other alternatives that the consumer may have observed while deciding on not attending a performance. For such instances, the price and the seats sold for each alternative are specified as the average prices and the average sales observed for that alternative over all transactions corresponding to that concert, respectively.

${ }^{4}$ The theory of reference-dependent riskless choice, presented in Tversky and Kahneman (1991), suggests that the utility of an alternative from dimension $k$ with reference point $r_{k}$ can be captured by some form of a reference function $R_{k}\left(x_{k}\right)$, which is given by

$$
R_{k}\left(x_{k}\right)= \begin{cases}u_{k}\left(x_{k}\right)-u_{k}\left(r_{k}\right) & \text { if } x_{k} \geq r_{k} \\ \lambda_{k}\left[u_{k}\left(x_{k}\right)-u_{k}\left(r_{k}\right)\right] & \text { if } x_{k}<r_{k}\end{cases}
$$

as long as there exists a function $u_{i}: x_{i} \rightarrow$ Reals. Thus, the asymmetric change in the utility by a shift of reference is described in terms of constant, $\lambda_{k}$, which can be interpreted as the coefficient of loss aversion for dimension $k$.
} 
(1991), which is given by

$$
R_{\text {Price }}\left(P_{i j t}\right)= \begin{cases}\log \left(R P_{i j t}\right)-\log \left(P_{i j t}\right) & \text { if } P_{i j t} \leq R P_{i j t}, \\ \lambda_{\text {Price }}\left[\log \left(R P_{i j t}\right)-\log \left(P_{i j t}\right)\right] & \text { if } P_{i j t}>R P_{i j t},\end{cases}
$$

where $\lambda_{\text {Price }}$ can be interpreted as the coefficient of loss aversion for price. Let $\beta_{\text {Price }}$ represents the impact of the change in price reference effects on the utility. Then, the utility from price reference effects for alternative $j$ can be stated as $\beta_{\text {Price }} R_{\text {Price }}\left(P_{i j t}\right)=\beta_{3} P G A I N_{i j t}+\beta_{4} P L O S S_{i j t}$, where $\beta_{3}=\beta_{\text {Price }}, \beta_{4}=-\beta_{\text {Price }} \lambda_{\text {Price }}$, and

$$
\begin{gathered}
\text { PGAIN } N_{i j t}= \begin{cases}\log \left(R P_{i j t}\right)-\log \left(P_{i j t}\right) & \text { if } P_{i j t} \leq R P_{i j t} \\
0 & \text { otherwise }\end{cases} \\
\text { PLOSS }_{i j t}= \begin{cases}\log \left(P_{i j t}\right)-\log \left(R P_{i j t}\right) & \text { if } R P_{i j t}<P_{i j t} \\
0 & \text { otherwise. }\end{cases}
\end{gathered}
$$

Thus, $P G A I N$ represents gain in utility due to a reduction in prices (with respect to reference prices) and PLOSS represents loss in utility due to a price that is higher than reference price. Let $x^{+}$denote $\max (x, 0)$. Our model also implicitly captures the main price effect in utility since $\beta_{3} P G A I N_{i j t}+\beta_{4} P L O S S_{i j t}$ can be rewritten as $\left(\beta_{3}+\beta_{4}\right)\left[\log \left(R P_{i j t}\right)-\log \left(P_{i j t}\right)\right]^{+}+\beta_{4}\left(\log \left(P_{i j t}\right)-\right.$ $\left.\log \left(R P_{i j t}\right)\right)$.

Sales Gain and Loss. Past research and popular media have shown that consumers may have different utility and behavior for well-attended events and prime locations (see Becker 1991 and Tanner 2014). In addition to the ticket pricing information, consumers who attend less frequently might use the crowdedness of certain seating zones to infer the differential quality of zones. In particular, a customer experiences a gain at a seating zone, when the observed sales at that location are higher than his reference value, which would increase the perceived worthiness of the zone and the likelihood of future purchases. Analogously, a consumer experiences a loss when the number of seats sold as a fraction of capacity is less than his reference for the zone.

As above, we calculated the utility gains and losses for seats sold (SGAIN and SLOSS) using 
the log transformations of fractional odds. As noted, we measure sales as the number of seats sold as a fraction of the capacity of the zone. ${ }^{5}$ In line with Tversky and Kahneman (1991), we formulate the sales reference effect $\left(R_{\text {Sales }}().\right)$ as

$$
R_{\text {Sales }}\left(S_{i j t}\right)= \begin{cases}\log \left(S_{i j t} /\left(1-S_{i j t}\right)\right)-\log \left(R S_{i j t} /\left(1-R S_{i j t}\right)\right) & \text { if } R S_{i j t} \leq S_{i j t}, \\ \lambda_{\text {Sales }}\left[\log \left(S_{i j t} /\left(1-S_{i j t}\right)\right)-\log \left(R S_{i j t} /\left(1-R S_{i j t}\right)\right)\right] & \text { if } R S_{i j t}>S_{i j t}\end{cases}
$$

where $\lambda_{\text {Sales }}$ represents the coefficient of loss aversion for sales. Let $\beta_{\text {Sales }}$ be the impact of the change in sales reference effects on the utility. We can write the utility from sales reference effects for alternative $j$ as $\beta_{\text {Sales }} R_{\text {Sales }}\left(S_{i j t}\right)=\beta_{5} S G A I N_{i j t}+\beta_{6} S L O S S_{i j t}$, where $\beta_{5}=\beta_{\text {Sales }}, \beta_{6}=$ $-\beta_{\text {Sales }} \lambda_{\text {Sales }}$, and

$$
\begin{aligned}
& \operatorname{SGAIN}_{i j t}= \begin{cases}\log \left(S_{i j t} /\left(1-S_{i j t}\right)\right)-\log \left(R S_{i j t} /\left(1-R S_{i j t}\right)\right) & \text { if } R S_{i j t} \leq S_{i j t}, \\
0 & \text { otherwise }\end{cases} \\
& \text { SLOSS } S_{i j t}= \begin{cases}\log \left(R S_{i j t} /\left(1-R S_{i j t}\right)\right)-\log \left(S_{i j t} /\left(1-S_{i j t}\right)\right) & \text { if } S_{i j t}<R S_{i j t} \\
0 & \text { otherwise. }\end{cases}
\end{aligned}
$$

This setup also implicitly captures the main sales effect in utility since $\beta_{5} S G A I N_{i j t}+\beta_{6} S L O S S_{i j t}$ can be rewritten as $\left(\beta_{5}+\beta_{6}\right)\left[\log \left(S_{i j t} /\left(1-S_{i j t}\right)\right)-\log \left(R S_{i j t} /\left(1-R S_{i j t}\right)\right)\right]^{+}+\beta_{6}\left(\log \left(R S_{i j t} /(1-\right.\right.$ $\left.\left.\left.R S_{i j t}\right)\right)-\log \left(S_{i j t} /\left(1-S_{i j t}\right)\right)\right)$.

\subsection{Framework for Price and Seat Sales Reference Formation}

We set up two simultaneous equations: one for reference price $\left(R P_{i j t}\right)$ and the other reference for seats sold $\left(R S_{i j t}\right)$, to explain how consumers form their multi-attribute reference levels together. In the marketing literature, a large number of papers on reference prices have demonstrated the existence of reference point effects by focusing mostly on price as the focal attribute (e.g., Krishnamurthi et al. 1992, Lattin and Bucklin 1989, and Kalyanaram and Little 1994). For more on reference price models, see Briesch et al. (1997). These studies infer reference price as a function

\footnotetext{
${ }^{5}$ Note the usage of odds on the sold seats as fraction of the zone capacity, prior to log transformation, i.e., $R S_{i j t} /\left(1-R S_{i j t}\right)$ instead of $R S_{i j t}$. This representation of the seats solds as fractional odds instead of just fractions, expands the support from $[0,1]$ to $[0, \infty)$, aiding econometric analysis but without any interpretive drawbacks.
} 
of past prices or current prices. In our model, consumers also use the information from the past observed prices and observed sales to form their reference levels on price and sales, respectively (Section 2.4). Another stream has demonstrated that the reference levels can be formed based on past prices, and external factors such as store characteristics and time related trends (e.g., Kalwani et al. 1990). In our model, consumers also use information on remaining weeks to the performance at the time of their purchase, and performance day and seating zone characteristics to form their price and sales reference levels. Hardie et al. (1993) consider formation of multi-attribute reference levels on price and quality of orange juice product. In their setting, the reference levels are formed independent of each other because the quality ratings for the orange juice products were already available from the ConsumerReports.org. In our setting, consumers can infer the price level by looking at information related with price, or can infer the sales level by looking at information related with sales. Thus, we contribute to this stream by allowing the multi-attribute reference levels to be formed based on each other.

We account for the link between the price and sales reference levels using a general functional form. However, note that a consumer's information on price and seats sold are not only different from each other, but they can also change across zones, performing days, throughout the season, and based on some unobserved characteristics which may influence their decisions (Köszegi and Rabin 2006). We account for all of these potential sources of variation using the following non-linear functional form,

$$
\begin{aligned}
& R P_{i j t}=\left(R S_{i j t} /\left(1-R S_{i j t}\right)\right)^{\alpha_{1}} \exp \left(\alpha_{0}+\alpha_{2} P A S T P r_{i j t}+\alpha_{3} \text { RemWeek }_{i j t}+d_{p j}+z_{p j}+u_{i j t}\right) \\
& R S_{i j t} /\left(1-R S_{i j t}\right)=\left(R P_{i j t}\right)^{\gamma_{1}} \exp \left(\gamma_{0}+\gamma_{2} \text { PASTSt } t_{i j t}+\gamma_{3} \text { RemWeek }_{i j t}+d_{s j}+z_{s j}+v_{i j t}\right)
\end{aligned}
$$

where RemWeek $k_{i j t}$ is time measured in remaining weeks to concert $t$ at the instance of purchase (as consumers may update their reference levels as it gets closer to the event), and $d_{p j}$ and $z_{p j}$ are fixed effects for concert day and seating zone for equation (11), respectively, and $d_{s j}$ and $z_{s j}$ are fixed effects for concert day and seating zone for equation (12), respectively which may influence consumer referencing, and $u_{i j t}$ and $v_{i j t}$ are i.i.d unobservable factors that affect the price and sales references of consumer $i$ for choice alternative $j$ at purchase instance $t$ with $\mathbb{E}\left(u_{i j t}\right)=0$ and 
$\mathbb{E}\left(v_{i j t}\right)=0$. Taking the $\log$ on both sides simplifies the equations further and give us the following functional forms,

$$
\begin{aligned}
& \log \left(R P_{i j t}\right)=\alpha_{0}+\alpha_{1} \log \left(R S_{i j t} /\left(1-R S_{i j t}\right)\right)+\alpha_{2} P A S T P r_{i j t}+\alpha_{3} \operatorname{RemWee}_{i j t}+d_{p j}+z_{p j}+u_{i j t} \\
& \log \left(R S_{i j t} /\left(1-R S_{i j t}\right)\right)=\gamma_{0}+\gamma_{1} \log \left(R P_{i j t}\right)+\gamma_{2} P A S T S t_{i j t}+\gamma_{3} \text { RemWeek }_{i j t}+d_{s j}+z_{s j}+v_{i j t}
\end{aligned}
$$

However, we have two remaining issues that need to be addressed, before we can estimate the multi-column vectors $\alpha$ and $\gamma$.

First, note that our model allows for consumers to use information on seat sales to build price reference points and price information to build sales reference points, leading to possible endogeneity. To address this endogeneity, we need some unique variable for each attribute with reference dependence. PASTPr $r_{i j t}$ and PASTSt $t_{i j t}$ capture the information on past prices and sales observed for alternative $j$ in concerts prior to the ticket purchase instance $t$, respectively.

Second, note that the covariates $\log \left(R P_{i j t}\right)$ and $\log \left(R S_{i j t} /\left(1-R S_{i j t}\right)\right)$ are both individual reference levels and are unobservable variables. Hence, we employ a framework to estimate the parameters by suitably modeling the variations in the unobservable reference points.

\subsection{Addressing Endogeneity}

To address endogeneity, we use the information from the past observed prices and observed sales as cofactors, in price and sales reference equations, respectively. We formulate the $P A S T P r_{i j t}$ and the PASTSt $t_{i j t}$ variables by using an exponential smoothing model that allows for quantifying the "speed of memory-adjustment process" (see Popescu and Wu 2007, p. 417). Thus, we assume that the updating mechanism for $P A S T P r_{i j t}$ and $P A S T S t_{i j t}$ is given by

$$
\begin{aligned}
\text { PASTPr }_{i j t} & =\theta P A S T P r_{i j t-1}+(1-\theta) P_{i j t-1} \\
\text { PASTSt } & =\theta \text { PPASTSt } \\
i j t-1 & +(1-\theta) S_{i j t-1}
\end{aligned}
$$

where $\theta$ is the exponential smoothing parameter. Following Popescu and $\mathrm{Wu}(2007)$, we address $\theta$ as the memory parameter, and consider the covariates PASTPr $r_{i j t}$ and PASTSt $t_{i j t}$ as a representation of consumer memories of past prices and past sales. $\theta$ captures how strongly these memories depend 
on past observations. ${ }^{6}$ For $\theta=0$, the consumer remembers only the most recent past price, and as $\theta$ increases, consumers use more of the past price observations. In our estimation, we choose a $\theta$ that provides the best overall fit in estimation of the price and sales reference model.

To estimate all the parameters in equations (11) and (12), we need the number of equations (two here) to equal (or exceed) the number of endogenous variables (which is also two). Thus, showing PASTPr $r_{i j t}$ and PASTSt $t_{i j t}$ are exogenous would be sufficient (but not necessary) to prove the completeness of the system.

Note that, even though $P A S T P r_{i j t}$ and PASTSt $t_{i j t}$ are clearly not exogenous, they are predetermined with respect to the current values of price and sales. Regressors that are predetermined in a model can be treated as if they are exogenous at least asymptotically, in the sense that consistent estimators can be derived (Greene 2011). Hence, the system of equations (11) and (12) is a complete system, where $P A S T P r_{i j t}$ and $P A S T S t_{i j t}$ serve as instrumental variables.

\subsection{Addressing Unobservability of Reference Levels}

Since reference thresholds $R P_{i j t}$ and $R S_{i j t}$ are both unobservable, we need to find equivalent observable substitutes. Even though the references are unobservable, we can exploit the fact that an individual can make errors in guessing the actual prices or sales because of errors originating in inertia or ignorance (see Zellner et al. 1966 as one of the early considerations of the difference between anticipated and realized prices in estimation of production models, and Kalwani et al. 1990 for use of this difference to replace the unobserved anticipations with realized prices to aid in estimation of the reference levels). These errors, resulting in deviations from the realized prices, can vary over time for every individual in the population (i.e., they are noisy across the population), but collectively they will cancel out. Then, we can write,

$$
\log \left(P_{i j t}\right)=\log \left(R P_{i j t}\right)+\epsilon_{i j t},
$$

\footnotetext{
${ }^{6}$ Recall that consumers may choose to skip a performance (outside option), and in this analysis we allow the observed prices and sales of other alternatives to be averages of prices and sales observed in other transactions corresponding to that performance. Under these circumstances, consumer may not update their past prices or sales memories at all. To capture this feature with an exponential smoothing mechanism, we may allow the consumers to focus on recent memories with actual purchases rather than past memories of choices of outside option. We run this extension of our model in Subsection 4.5.2 and reach the same theoretical conclusions on loss aversion.
} 
where the $R P_{i j t}$ is the price reference point and $\epsilon_{i j t}$ is an i.i.d. unobservable factor that represents the error in consumer $i$ 's guess of the price for choice alternative $j$ at purchase instance $t$, and $\mathbb{E}\left(\epsilon_{i j t}\right)=0$.

Similarly, we can define the reference point on seats sold by,

$$
\log \left(S_{i j t} /\left(1-S_{i j t}\right)\right)=\log \left(R S_{i j t} /\left(1-R S_{i j t}\right)\right)+\psi_{i j t}
$$

with $\mathbb{E}\left(\psi_{i j t}\right)=0$. Finally, we assume that $\mathbb{E}\left(\epsilon_{i j t} X_{i j t}\right)=0$ and $\mathbb{E}\left(\psi_{i j t} Z_{i j t}\right)=0$, where $X_{i j t}=$ $\left\{R S_{i j t}, P A S T P r_{i j t}\right.$, RemWeek $\left._{i j t}, d_{j}, z_{j}\right\}$ and $Z_{i j t}=\left\{R P_{i j t}, P A S T S t_{i j t}\right.$, RemWeek $\left._{i j t}, d_{j}, z_{j}\right\}$.

Once we substitute the unobservable variables in equations (11) and (12) with the actual realizations from equations (15) and (16), we end up with the following system of equations for estimation:

$\log \left(P_{i j t}\right)=\alpha_{0}+\alpha_{1} \log \left(S_{i j t} /\left(1-S_{i j t}\right)\right)+\alpha_{2} P A S T P r_{i j t}+\alpha_{3} \operatorname{RemWee}_{i j t}+d_{p j}+z_{p j}+u_{i j t}+\epsilon_{i j t}-\alpha_{1} \psi_{i j t}$

$\log \left(S_{i j t} /\left(1-S_{i j t}\right)\right)=\gamma_{0}+\gamma_{1} \log \left(P_{i j t}\right)+\gamma_{2} P A S T S t_{i j t}+\gamma_{3} R e m W e e k_{i j t}+d_{s j}+z_{s j}+v_{i j t}+\psi_{i j t}-\gamma_{1} \epsilon_{i j t}$

As pointed out earlier, due to inter-dependencies in reference points, both equations (17) and (18) are required to calibrate the estimates. Further, the first two terms in the five-part error structure in the above equations capture the differences due to fixed performance-day and seating zone effects, respectively. The last three terms in equations (17) and (18) are i.i.d random errors with zero mean and finite variance. Thus, the consideration of individual based errors in anticipation of prices aids in replacing the unobservable price and sales reference points with their actual realizations.

\subsection{Estimation Scheme}

In this section, we provide stepwise details of how all the parts of estimation approach fit together.

1. Note that the covariates in equations (17) and (18), specifically, $P_{i j t}$ and $S_{i j t}$, and $P A S T P r_{i j t}$ and PASTSt $t_{i j t}$, are observable. We get $P_{i j t}$ and $S_{i j t}$ directly from the data and put in place of $R P_{i j t}$ and $R S_{i j t}$, as described in Section 2.5. 
2. We obtain $P A S T P r_{i j t}$ and $P A S T S t_{i j t}$ from exponential smoothing in equations (13) and (14) in Section $2.4 .^{7}$

3. We are now ready to estimate $\alpha$ and $\gamma$ vectors (parameters) from equations (17) and (18). However, the error terms in the system could be correlated across equations. Hence, we use the three-stage least squares (3SLS) estimation method to resolve the potential correlation issues between the disturbance terms, while estimating the $\alpha$ and $\gamma$ parameters.

4. We use the estimates $\hat{\alpha}$ and $\hat{\gamma}$ and the equations (15) and (16) to compute the reference levels $\widehat{\log \left(R P_{i j t}\right)}$ and $\log \widehat{\left(\frac{R S_{i j t}}{1-R S_{i j t}}\right)}$, as described in equations (11) and (12) in Section 2.3. ${ }^{8}$

5. We plug the reference levels we obtained in the above step in the calculation of gains and losses, as provided in equations (4), (5), (7), and (8) in Section 2.2.

6. We use the computed estimates $P \widehat{G A I N}_{i j t}, P \widehat{L O S S}_{i j t}, S \widehat{S A I N}_{i j t}$ and $S \widehat{L O S S}_{i j t}$ to obtain the reference-dependent utilities $v_{i j t}$ in equation (1) in Section 2.1.

7. Using the reference-dependent utilities from equation (1), we find the maximum likelihood estimators for $\beta, \delta_{z}$, and $\delta_{d}$ through the multinomial logit model (described in equation (2)). We estimate the model using the non-linear maximum likelihood estimation solver, maxLik (Henningsen and Toomet 2011), with an R interface.

Following the above sequence, we are able to calibrate the choice probabilities for customer $i$ to select an alternative $j$ for a concert $t$ under reference-dependent preferences. With our estimation approach for reference-dependent choices in hand, we now examine the context of our application.

\section{Data}

We test for reference-dependent decisions on data of individual-level ticket transactions collected during three seasons at a renown symphony orchestra in Northeastern United States. The data

\footnotetext{
${ }^{7}$ We use the observed prices and sales in the first two concerts in our estimation sample to allow the consumers to build their memories on prices and sales for the third concert. Then, we use the remaining concerts in the estimation sample to run our two-step choice model. This procedure allows us a sufficient time span to build up the memories in accordance with their actual observations. Using the listing prices and the peak capacity as the initial reference levels may have biased our results in case the price and sales reference effects have downward variability.

${ }^{8}$ We denote the estimated parameters for $x$ by $\hat{x}$.
} 
covers each choice alternative from several departments and at ticket booths. Each recorded transaction in the data reflects not only the number of tickets sold, but also their price.

Our data covers ticket sales for three seasons from 2008 to 2010 (henceforth referred to as Seasons 1, 2, and 3, respectively), with each season consisting of 21 weeks of concerts. In each week, multiple shows of the same repertoire are performed on different days - typically on Fridays and Saturdays; and occasionally on Thursdays and/or Sundays. Including all performance days, there are a total of 53 performances during the 21 weeks, which is considered a full season.

In each of the 21 weeks, a different musician presents a distinct repertoire, with most of the shows conducted by the orchestra conductor. As the orchestra is renown for its quality and selection, the utility of the consumers at the concert has a significant experiential component and intrinsic variability.

The venue has a maximum seating capacity of $2,600+$ seats. It has eight seating areas numbered $(1,2, \ldots, 8)$ in our data. The tiers are determined by "seat quality" factors associated with the seating area: the acoustic experience and the visual line of sight to the stage. There is a significant price difference between the seating zones. ${ }^{9}$ See from the lower half of Table 1 , that there is a significant variation in the observed number of seats sold as a fraction of capacity for concerts, which allows us to use seats sold as a covariate in our estimation.

The customer pool can be classified into subscribers and single-ticket buyers. Subscribers can buy ticket packages for 7, 14, or 21 performances. Thus, subscribers commit to purchase different pre-set quantities of tickets. Since subscribers commit a fixed payment to a certain package of shows, they do not make repeated decisions based on the fluctuation of single-ticket prices, and hence we exclude subscribers from our analysis on repeat purchases.

Our focal customer category consists of "single ticket buyers" who may buy tickets to multiple shows; however, they purchase their tickets to each of them, individually. The list ticket prices depend only on the day of the concert and the seating zone, regardless of the repertoire performed. For instance, on Fridays when the prices are at their maximum, the high-priced seating zones are always sold at an advertised ticket price of $\$ 82.50$ and the lowest-priced zone ticket is about $\$ 19.50$ (see Table 1).

\footnotetext{
${ }^{9}$ The high-level pricing decision is based on second-degree price discrimination. The theater management announces the base prices for the seating areas at the beginning of every season.
} 


\subsection{Preliminary Processing for Calibration and Validation}

The transaction data file includes 27,894 ticket buyers who made a total of 269,791 ticket purchases during the three seasons of data collection period; 14,737 out of those customers are single-ticket buyers who made a total of 47,119 purchases. We further exclude customers who rarely attend symphony concerts (i.e., less than two concerts in any season of 21 concerts). ${ }^{10}$ The final sample includes 149 customers who made a total of 3,370 ticket purchases. The purchase records for 63 weeks of concerts are separated into two mutually exclusive parts for estimation and counterfactual analysis. The purchase records for concerts in Seasons 1 and 2 and the first 14 concerts of Season 3 (the last season) are used for calibration. The purchase records for the remaining 7 concerts during Season 3 are used for the counterfactual price experiments.

\begin{tabular}{cccccc}
\hline Variables & Zones & Mean & Std. dev. & Min. & Max. \\
\hline \multirow{4}{*}{$P$} & 1 & 46.32 & 22.68 & 6.92 & 82.50 \\
& 2 & 36.96 & 18.07 & 5.75 & 67.00 \\
& 3 & 30.84 & 14.90 & 4.92 & 52.50 \\
& 4 & 29.38 & 14.30 & 4.42 & 52.00 \\
& 5 & 27.54 & 13.44 & 4.08 & 47.50 \\
& 6 & 22.73 & 11.27 & 3.17 & 40.00 \\
& 7 & 15.48 & 7.48 & 2.50 & 26.50 \\
$S$ & 8 & 11.36 & 5.45 & 2.00 & 19.50 \\
\hline & 1 & 0.76 & 0.15 & 0.21 & 1.00 \\
& 2 & 0.74 & 0.15 & 0.16 & 1.00 \\
& 3 & 0.72 & 0.16 & 0.13 & 1.00 \\
& 4 & 0.79 & 0.17 & 0.13 & 1.00 \\
& 5 & 0.59 & 0.21 & 0.07 & 0.99 \\
& 6 & 0.57 & 0.27 & 0.02 & 1.00 \\
& 7 & 0.64 & 0.24 & 0.06 & 1.00 \\
& 8 & 0.56 & 0.24 & 0.05 & 0.95 \\
\hline
\end{tabular}

Table 1: Summary statistics for prices $(P)$ and seats sold $(S)$ observed prior to purchase.

Now, we are ready to summarize the data with respect to variables defined in the model developed in Section 2. Prices vary throughout the season, and the discount received by a customer for a show depends on the time of purchase. Since we also know the discount rate and the list-price zones, we can obtain the discounted prices that will be observed for other alternatives (i.e., $P_{i j t}$ across all $j$ for a given concert $t$ ). Further, since all purchases are observed, we can immediately calculate

\footnotetext{
${ }^{10}$ Repeat purchases are vital for a customer to remember past observations and build reference points. Because of a potential lack of memory on prices and sales with only one purchase throughout the season, we exclude them from our analysis.
} 
the fraction of seats sold for every seating zone-day alternative at the time of purchase (i.e., $S_{i j t}$ ). Table 1 includes some descriptive statistics for these variables over the calibration period.

\section{Results}

We first explore the result of the joint price-sales references model as in equations (17) and (18). The results of the model are summarized in Table 2. The left part of Table 2 presents the estimates for price references based on observations and past history. The right part of Table 2 presents the estimates for references on seats sold based on observations and past history.

Note that most of the estimates of interest are significant. We provide the goodness-of-fit measures for both price and sales equations in Table 2. We find that we obtain the highest value of goodness-of-fit for our model when the memory parameter is $\theta=0.8$. We find that significant fraction of the variation in $P_{i j t}$ and $S_{i j t}$ can be predicted through the factors we proposed for all seating zones with adjusted coefficients of determination (adjusted- $\mathrm{R}^{2}$ ) for the price and sales equations as 0.579 and 0.295 , respectively. In what follows, we first interpret the estimates of covariates that influence price references and then similarly discuss the effects on sales references.

\subsection{Price References}

Note that the observation of seats sold drives the price references significantly. The effect of sales (as a fraction of capacity) on the expected price is non-linear. All else equal, if the fractional odds on seats sold increases by $1 \%$, a customer's price reference levels changes by about $-0.06 \%$. For instance, if the seats sold in a zone increases from 0.90 (of the capacity of the zone) to 0.95 , then the customers' price reference levels would change by $\left((19 / 9)^{-0.062}-1\right) \times 100=-4.52 \%$.

The past prices recalled by consumers play a strong role in the future anticipations. In other words, if the consumers saw higher prices in the past, they expect to see higher prices in the future, and vice versa. This observation strengthens the notion of possible reference-driven consumer behavior.

In our application, consumers expect the prices to decrease very slightly as they get closer to the performance: a consumer who purchases a ticket one week later than usual, typically expects the price to be lower by $\left(e^{0.007}-1\right) \times 100=0.70 \%$. Finally, consumers expect tickets to be 
more expensive on Fridays and Saturdays than on Thursdays. This is also reflected in how the organization sets the list prices.

\begin{tabular}{lclc}
\hline Coefficients & $\begin{array}{c}\text { Price Model } \\
(\text { eqn. 17) }\end{array}$ & Coefficients & $\begin{array}{c}\text { Sales Model } \\
\text { (eqn. 18) }\end{array}$ \\
\hline Intercept & $1.763(0.030)^{* * *}$ & Intercept & $-2.198(0.214)^{* * *}$ \\
$\log (S /(1-S))$ & $-0.062(0.006)^{* * *}$ & $\log (P)$ & $-0.155(0.043)^{* * *}$ \\
PASTPr & $0.031(0.001)^{* * *}$ & PASTSt & $5.737(0.125)^{* * *}$ \\
RemWeek & $0.007(0.001)^{* * *}$ & RemWeek & $-0.054(0.001)^{* * *}$ \\
Thu & $-0.095(0.015)^{* * *}$ & Thu & $0.097(0.059)$ \\
Sat & $-0.012(0.006)^{* *}$ & Sat & $-0.041(0.022)^{*}$ \\
Sun & $0.092(0.007)^{* * *}$ & Sun & $0.156(0.025)^{* * *}$ \\
\hline Adj. $\mathrm{R}^{2}$ & 0.579 & Adj. $\mathrm{R}^{2}$ & 0.295 \\
\hline
\end{tabular}

Notes. Left (right) of the table shows the estimates for the price (sales) equation of the simultaneous price and sales references model. Standard errors are shown in parentheses. ${ }^{*}$, ** and *** denote significance at the $10 \%, 5 \%$ and $1 \%$, respectively. The price and sales equations also include seating area fixed effects.

Table 2: Estimation results for price and sales references model

\subsection{References on Seats Sold (Capacity Sold)}

The reference on how much capacity will be sold in a seating zone is driven by the observed prices. Consistent with intuition, if the observed price in a zone is higher, the consumers' references on the seats sold as a fraction of capacity in that section will be lower. Specifically, if the observed price is higher by a percentage point at a seating zone that is $80 \%$ full, the fraction of capacity filled is expected to decrease to $79.97 \%$. The fractional odds of seats sold in a section decreases by $\left((1.01)^{-0.155}-1\right) \times 100=-0.15 \%$, which is $\sim 1 \%$ when $80 \%$ of the capacity filled in the section.

A consumer's past observations on the seats sold in a zone strongly drives his or her future references on the seats that will be sold in that zone. If the sales recalled from past observations are high (low) for a consumer, then she expects that the future seat sales in the zone continue to be high (low). This effect of past observations is distinct from loyalty to a seating zone - regardless of the zones a consumer purchases seats in, she continues to develop reference levels on seats sold in other zones, based on her past observations.

Not surprisingly, consumers expect the seats sold in every zone to increase as they get closer to the performance day. If the capacity is $80 \%$ full in a seating zone in a given week, in the next week the consumers expect the zone to be $80.81 \%$ full. 
Finally, consumers expect sales for a Saturday performance to be slightly lower relative to Friday performance of the same material. If the initial sales references for a Friday performance are $80 \%$, then references for Saturday performance would be $4 \times(1-0.041) /(1+4 \times(1-0.041))=79 \%$. This is consistent with observations that Fridays are the busiest concert evenings.

To summarize, consumers who observed lower prices and sales tend to expect to see lower prices and sales to continue in all seating zones. Thus, we find consistency in evidence that consumers may use past information as part of reference formation on prices and seats that will be sold in future. The effects of price-referencing (promotions, etc) have been documented in the marketing literature. We believe that the findings of reference effects on sales (filled capacity) are new.

\subsection{Evidence for Reference-Dependent Behavior}

We have established the formation of references that are driven by past observations of prices and sales, current observations, and other exogenous parameters. A main question is whether the reference dependence leads to choices that explain the observed information better than using a classical model without such reference dependence.

To do this we create a benchmark (or a null choice) model, which is the classic multinomial choice model without reference effects. The only covariates we consider are the fixed effects, loyalty variables for seating zone and performance day, and the prices for each alternative (as considered in typical MNL models). The results of the null model are presented in column (A) of Table 3. Column (B) presents the model with only price reference effects instead of absolute utilities. Column (C) reports the results on choices driven by reference dependence on both prices and seats sold. Note that the models (B) and (C) are not nested with (A).

We find that a model with some reference dependence consideration (in our case, reference dependence only on price) explains customer choices better than the benchmark choice model. We use the Akaike Information Criterion (AIC) and the Bayesian Information Criterion (BIC) to compare the models, because AIC and BIC do not require the models to be nested unlike the likelihood-ratio test. Let $A I C_{i}$ and $B I C_{i}$ be the AIC and BIC scores calculated for model $k \in\{A, B, C\}$ depicted in Table 3. The scores show that $A I C_{B}<A I C_{A}$ and $B I C_{B}<B I C_{A}$. Hence, the choice model with reference dependence only on prices provides a significantly better fit with data than the benchmark model. In other words, customer choices that are observed are 


\begin{tabular}{lccc}
\hline Coefficients & $\begin{array}{c}\text { Benchmark } \\
\text { (No reference effects) } \\
(\mathrm{A})\end{array}$ & $\begin{array}{c}\text { Price Reference } \\
\text { Effects } \\
(\mathrm{B})\end{array}$ & $\begin{array}{c}\text { Price and Sales } \\
\text { Reference Effects } \\
(\mathrm{C})\end{array}$ \\
\hline Logit coefficients: & & & \\
$Z L$ & $9.878(0.476)^{* * *}$ & $11.93(0.539)^{* * *}$ & $12.04(0.544)^{* * *}$ \\
$D L$ & $3.465(0.331)^{* * *}$ & $5.540(0.372)^{* * *}$ & $5.778(0.373)^{* * *}$ \\
Price & $-0.208(0.006)^{* * *}$ & - & - \\
PGAIN & - & $2.005(0.336)^{* * *}$ & $3.302(0.388)^{* * *}$ \\
PLOSS & - & $-10.82(0.305)^{* * *}$ & $-11.07(0.326)^{* * *}$ \\
SGAIN & - & - & $0.343(0.038)^{* * *}$ \\
SLOSS & - & - & $-0.586(0.064)^{* * *}$ \\
Smoothing constants: & & & \\
$\delta_{z}$ & $0.925(0.007)^{* * *}$ & $0.926(0.007)^{* * *}$ & $0.927(0.007)^{* * *}$ \\
$\delta_{d}$ & $0.857(0.024)^{* * *}$ & $0.852(0.018)^{* * *}$ & $0.857(0.016)^{* * *}$ \\
\hline Log Likelihood & -6310 & -5954.1 & -5858.8 \\
Adj. Fit Statistic & 0.327 & 0.365 & 0.375 \\
AIC & 12692.0 & 11982.2 & 11795.6 \\
BIC & 12954.6 & 12251.9 & 12079.4 \\
\hline
\end{tabular}

Note. Standard errors are shown in parentheses. $* * *$ denotes significance at the $1 \%$ confidence level. All models include zone-day fixed effects. Alternatively, adoption of Fader et al.'s (1992) procedure for this estimation also provides almost the same estimates for these choice models.

Table 3: Estimation results for consumer choice models

better explained by reference-dependent preferences.

\subsection{Evidence for Reference Dependence on Multiple Attributes}

At this juncture, we ask if there is strong evidence for multi-attribute reference-dependent choice behavior. Second, we are also interested if sales based reference levels, in particular, drive customer decisions (over and above the price dependencies).

We answer the first question by comparing the AIC and BIC scores of the multi-attribute reference effects model we have developed so far with the model which involves only price reference effects. Scores in Table 3 show that $A I C_{C}<A I C_{B}$ and $B I C_{C}<B I C_{B}$. In other words, the multiattribute (price and sales) reference effect model provides a significantly better fit than the model with only price reference effects in explaining consumers' choice decisions. The results provide support for reference dependence on multiple attributes. We know of only one other paper (Hardie et al. 1993) that examines the multi-attribute loss aversion in prices and quality (both assumed to be exogenous) in the context of orange juice sales, which happen pretty frequently for every 
customer. Note that in our context the multi-attribute reference dependence helps us to explain the data even though a consumer on the average visits the venue only 3.5 times and her sales references are endogenous and unobservable.

We find that the additional fit explained with our multi-attribute reference model compared to the single attribute reference model does not come from other covariates. Comparing $Z L, D L, \delta_{z}$, and $\delta_{d}$ between columns $(\mathrm{C})$ and $(\mathrm{B})$ in Table 3 show that there is no significant change in the value of the estimates for these covariates. Rather, the additional explanation comes from $(i)$ sales gain and loss (SGAIN and SLOSS), and (ii) improved calibration of price reference effects (PGAIN and PLOSS).

\subsubsection{Cross-Validation for Reference Dependence on Multiple Attributes}

We also use ten-fold cross validation with stratification to show the improvement in the ability of the model to predict the choice behavior of customers after the inclusion of the price and sales reference effects (Kohavi 1995). The improvement will be an additional evidence for multi-attribute reference-dependent choice behavior in this setting. The validation is done for the choice model with no reference effects (column (A) of Table 3) and for the choice model with price and sales reference effects (column (C) of Table 3) in isolation.

Let $\Psi_{k t}$ denote all the performance day-seating zone alternatives which includes seating zone $k$ for concert $t$. To get one customer's choice probability for zone $k$, we need to add up this customer's choice probabilities of all alternatives which contain seating zone $k$. Let $P_{i k t}$ denote customer $i$ 's probability of choosing zone $k$ for concert $t$, which is given by $P_{i k t}=\sum_{h \in \Psi_{k t}} \mathbb{P}_{i h t}$.

The customer's decisions to choose for each concert are independent of each other. Therefore, the predicted choices for each seating zone in concert $t$ has a multinomial distribution. Let $m_{i k t}$ and $\sigma_{i k t}$ denote the mean and standard deviation of choices for seating zones $k=1, . ., 8$ for this distribution, respectively. Then, $m_{i k t}=P_{i k t}$ and $\sigma_{i k t}=\sqrt{P_{i k t}\left(1-P_{i k t}\right)}$. Let $N$ be the set of indexes of customers who involve in repetitive purchases throughout the season in each fold and $T$ be the set of indexes of concerts in the estimation sample. Then, the predicted number of aggregate choices for seating zone $k$ is $\sum_{t \in T} \sum_{i \in N} m_{i k t}=\sum_{t \in T} \sum_{i \in N} P_{i k t}$. Let $a_{k t}$ denote the actual number of choices for seating zone $k$ for concert $t$.

We consider the average absolute errors in predicting the aggregate choice rates for each seating 
zone as the performance metrics for the cross-validation. This metric is given by

$$
\text { Absolute } \text { Error }_{k}=\frac{1}{N}\left|\sum_{t \in T} \sum_{i \in N} m_{i k t}-\sum_{t \in T} a_{k t}\right|
$$

We calculate the averages of the performance metric across all test sets for the choice models with and without price and sales reference effects in Table 4, which shows an improvement in the ability of the model to predict the choice behavior after the inclusion of the price and sales reference effects except for seating zone 8. Improvement observed for majority of the seating zones is a clear indication of multi-attribute reference-dependent choice behavior in this setting.

\begin{tabular}{|c|c|c|}
\hline \multirow{3}{*}{ Zones } & \multicolumn{2}{|c|}{ Absolute Errors } \\
\hline & No & Price and Sales \\
\hline & Reference Effects & Reference Effects \\
\hline 1 & 0.31 & 0.19 \\
\hline 2 & 0.29 & 0.33 \\
\hline 3 & 0.42 & 0.39 \\
\hline 4 & 0.21 & 0.22 \\
\hline 5 & 0.36 & 0.31 \\
\hline 6 & 0.23 & 0.18 \\
\hline 7 & 0.21 & 0.18 \\
\hline 8 & 0.19 & 0.32 \\
\hline
\end{tabular}

Table 4: Averages of the performance metric across all test sets for the choice models with and without price and sales reference effects.

\subsection{Evidence for Loss Aversion}

Given that our multi-attribute reference-dependent choice model is shown to perform better in explaining customers' choice decisions, we can now focus on the question of loss aversion on prices and seats sold.

Results of the test of symmetry in consumer response to deviations of the price from the expected price reveals that consumers react more strongly to price losses (-11.07) than to price gains (3.302). An asymptotic $t$-test of the difference in magnitude between price gain and price loss indicates that the difference is significant at the $\alpha=0.01$ level. We find that the loss aversion factor for reference dependence on ticket price is 3.35. Thus, consumers respond more negatively to increases in prices than they react positively to a similar drop in prices. The extant literature has already shown 
such price loss aversion in a variety of settings (see examples in Kalyanaram and Winer 1995). We extend this literature by showing the existence of loss aversion in prices in a new setting (experience goods).

Results of the test of symmetry in consumer response to differences between observations and references in seats sold also reveals that they react more strongly to losses in seats sold $(-0.586)$ than gains (0.343). An asymptotic t-test of the difference in magnitude between sales gain and sales loss indicates that the difference is significant at the $\alpha=0.01$ level. We find that the loss aversion for reference dependence on sales is 1.71. Consumers respond more negatively when they observe emptier-than-expected seating areas than they react positively to seating areas more crowded than their expectations.

\subsubsection{Inclusion of the Main Price and Sales Effects}

Following the sticker shock model introduced by Winer (1986), a stream of papers (Lattin and Bucklin 1989, Kalwani et al. 1990, Mayhew and Winer 1992, and Kalyanaram and Little 1994) in the marketing literature include the main price effect together with the difference between the observed price and the reference price of the consumer in the reference-dependent utility model. In this setting, the multi-attribute utility would be formulated by including the price and sales levels separately in equation (1) as below:

$$
\begin{array}{r}
v_{i j t}=\beta_{0 j}+\beta_{1} Z L_{i j t}+\beta_{2} D L_{i j t}+\beta_{3} P G A I N_{i j t}+\beta_{4} P L O S S_{i j t}+\beta_{5} S G A I N_{i j t}+\beta_{6} S L O S S_{i j t} \\
+\beta_{7} P_{i j t}+\beta_{8} S_{i j t} .
\end{array}
$$

The results from estimation of the choice model under the sticker shock modeling framework still show an evidence of loss aversion on both price and sales just like in our main model depicted in equation (1). We find the customers react more to higher prices (-12.16) than to lower prices (2.304) compared to their price references with both estimates being significant $(p<<0.01)$, and they react much more strongly to lower sales (-0.474) than to higher sales (0.316) in comparison to their sales references with both estimates being significant $(p<<0.01)$. The estimates for the main price and sales variables are -0.148 (with $p<<0.01$ ) and 0.882 (with $p<0.05$ ), respectively. In view of the same conclusions, we adhere to our original estimated model as depicted in column 
(C) of Table 3 to conduct the rest of the analysis.

\subsubsection{Concert Attendance and Updating Memories}

The past memories for prices and seats sold represented in equations (13) and (14) refer to a situation when consumers update their memories regardless of not attending a performance (the outside option). Some of these consumers may not update their past price or sales memories at all. Under these circumstances, model calibration using the same memory adjustment parameter regardless of observing some past choices of outside option introduces sources of heterogeneity that could potentially bias the estimates of loss aversion for both prices and sales.

If consumers' memories differ with respect to choosing an outside option or not, those who skip a couple of performances will tend to recall more recent memories rather than the far distant memories. As a result, those who skip frequently will experience gains and losses with prevailing prices and sales differently than those who attend most of the performances. Under these circumstances, it may be better to fit consumer choice behavior with two different memory adjustment parameters in equations (13) and (14) rather than using one parameter $\theta$ at every iteration.

In light of these concerns, we allow for different memory adjustment parameters in every iteration for calculation of $P A S T P r_{i j t}$ and $P A S T S t_{i j t}$. We use $\theta_{1}$ if a consumer chose an alternative other than the outside option in that iteration, and we use $\theta_{2}$ if a consumer chose the outside option. We use a grid search to find the two parameters that maximizes the fit of the choice model. The choice model achieved the best fit when $\theta_{1}=0.8$ and $\theta_{2}=0.6$. This shows that consumers have a tendency to forget past memories if they attend less frequently.

Most importantly, the results from estimation of the choice model with two separate memory adjustment parameters are still supportive of loss aversion on both prices and sales as in the case of a single memory adjustment parameter. Results of the test of symmetry in customer response to deviations of the price and the sales from the expected prices and sales reveal that customers react more strongly to price losses (-14.03) than to price gains $(4.032)$, and they react more strongly to losses in seats sold (-0.451) than to gains (0.206). These estimates are significant at the $\alpha=0.01$ level and an asymptotic t-test of the difference in magnitude between price gain and price loss, and sales gain and sales loss are still significant at the $\alpha=0.01$. In light of these similar results, we conduct the rest of the analysis with the estimates from the choice model with single memory 
adjustment parameter $(\theta=0.8)$ as in column $(\mathrm{C})$ of Table 3 .

\subsubsection{Accounting for Popular Performances in Price-Sales Reference Formation}

Even though all performances in a season are qualitatively similar to each other, some concerts are more popular for a variety of reasons, such as playing a brand new musical piece, etc. It is important to verify if loss aversion and reference-dependent behaviors sustain, when the underlying popularity of an event is considered.

We first try to identify the concerts which seem to be more popular relative to others by looking at their total sales performance. The organization sold on the average 1,975 seats per concert for Friday performances in our estimation sample and the standard deviation was approximately 350. We label the concerts with sales more than two standard deviations ${ }^{11}$ above the mean as the popular performances. Only six concerts qualify as popular performances according to this criteria. We add an indicator variable to both equations in the price and sales references model which gives one for these six performances, and 0 otherwise. As expected, we find positive and significant coefficient estimates for this variable (0.110 in the price equation and 1.102 in the sales equation). This shows that consumers have a tendency to anticipate higher prices and higher sales for popular concerts.

Estimation of the choice model after the inclusion of popularity variables within the price and sales references model still shows an evidence of loss aversion on both prices and sales just as in the case without the popularity variables. Customers weigh price losses (-10.70) more than price gains (3.447), and they react losses in seats sales (-0.564) more than gains (0.391). These estimates are significant at the $\alpha=0.01$ level and an asymptotic t-test of the difference in magnitude between price gain and price loss, and sales gain and sales loss are still significant at the $\alpha=0.01$.

\subsubsection{Accounting for Popularity in the Choice Model}

We also control for the event popularity in the choice step of our two-step model by estimating the price and sales reference effects separately for unpopular and popular events. We label the concerts with total sales for Friday performances higher than the median of total sales of Friday performances of all concerts in the estimation sample as popular performances, and the concerts

\footnotetext{
${ }^{11}$ We also analyzed concerts with sales of one standard deviation over the mean, and confirmed the existence of loss aversion and reference dependence on both attributes.
} 
with total Friday sales lower than the median as unpopular. Multi-attribute reference effects and loss aversion on price and sales persist for both unpopular and popular concerts. For unpopular concerts, consumers react more to price losses $(-12.48)$ than to price gains $(2.527)$, and more to sales losses (-0.420) than to sales gains (0.281). Similarly, for popular concerts, consumers weigh price losses (-10.60) more than price gains (3.433), and weigh sales losses (-0.377) more than sales gains (0.351). These estimates are significant at the $\alpha=0.01$ level and an asymptotic t-test of the difference in magnitude between gains and losses for prices and sales are significant at the $\alpha=0.01$ for both unpopular and popular concerts. We will use our base model with price and sales reference effects (with estimates depicted in column (C) of Table 3) to conduct subsequent analysis. One may notice how loss aversion on seat sales is slightly weaker (even though significant) for popular concerts. In our counterfactuals and policy discussions, we will discuss how the findings on popularity strengthen our main recommendations.

\subsection{Econometric Implications}

To assess the implications of the reference effects and loss aversion on ticket purchases, we computed the elasticities representing the impact of a $1 \%$ change in each of the covariates on the average consumer choice probabilities across all alternatives. The elasticities are 0.471 (PGAIN), -0.721 (PLOSS), $0.069(S G A I N)$, and -0.144 (SLOSS). These findings are consistent with the loss aversion findings in the previous section. Loss due to a price increase (PLOSS) has a bigger impact on the choice probability than gains due to a price lower than reference price $(P G A I N)$. Similarly, loss for an area which seems emptier than expected (SLOSS) has a bigger impact on choice probability than gain for the same area which seems more crowded than expected $(S G A I N)$.

Consider a small increment in the ticket price of a particular seating zone - say a $1 \%$ increase in the price. We want to explore the impact of this price change on an average consumer who arrives to purchase tickets. A $1 \%$ increase in price increases PLOSS by 0.01 . In our data, the weighted average PLOSS (measured in $\log (P)-\log (R P)$ ) is 0.10 , which increases to 0.11 (which is a $10 \%$ increase in PLOSS). As noted above, the elasticity of choice probabilities corresponding to PLOSS is -0.721 . So a $10 \%$ increase in PLOSS corresponds to $7.2 \%$ reduction (i.e., $10 \% \times-0.721$ ) in the probability of choosing that zone. Thus, a $1 \%$ change in the ticket price of a zone on average leads to an adverse effect of that zone being chosen with lower probability ( $7.2 \%$ on average). 
Now, we explore the effect of a change in the number of seats sold as a fraction of capacity, which a consumer observes prior to his decision, on the probability of purchasing from that zone. Suppose that the fraction of seats sold in a zone drops by $15 \%$ (e.g., from $50 \%$ to $42.5 \%$ ). We calculate the impact when sales are lower than expected for an average arriving customer. From our estimation results, due to sales-loss aversion, a $15 \%$ fall in the fraction of seats sold increases SLOSS by 0.26 . Again, from our data set, the average SLOSS variable is 0.38 (expressed in difference of log odds), which increases to 0.64 with a $15 \%$ drop in the seats sold as a fraction of capacity. A change in SLOSS from 0.38 to 0.64 is an $68 \%$ increase in SLOSS. Thus a $15 \%$ drop in sales in a zone (from $50 \%$ to $42.5 \%$ ) would produce a reduction of $9.79 \%$ (i.e., $68 \% \times-0.144$ - the elasticity of sales loss) in the average probability of choosing from that zone.

Finally, consider the smoothing constants, $\delta_{z}$ and $\delta_{d}$, that are embedded into the zone and day loyalty variables ( $Z L$ and $D L$, respectively). Having positive significant estimates confirms that their choices were not only informed by their last choice but by their choices in the past several visits. We observe that the loyalty factors on seating zone and the day of visit $(Z L$ and $D L)$ have a significant influence on the next choice. In other words, consumers have a tendency to go on the same day of the week for a performance. They also exhibit some preference to buy tickets in the seating zones they visited in the past. However, if they find that zone is emptier than expected on their visits, they are not likely to choose the zone again due to strong sales loss aversion effects.

\subsection{Counterfactuals}

We now explore the implications of how loss aversion and reference on multiple attributes affect the firm's operational policies - in setting prices for a concert or focusing on which zones to discount through counterfactual pricing experiments. Our goal is not to solve for the optimal state-dependent pricing scheme, but to provide some insights into levers that the firm needs to consider when selling to consumers who exhibit loss aversion.

To test for counterfactuals, we track the choices of customers for the last 7 concerts of Season 3 and use them as a holdout sample. Recall that customers choose among different alternatives

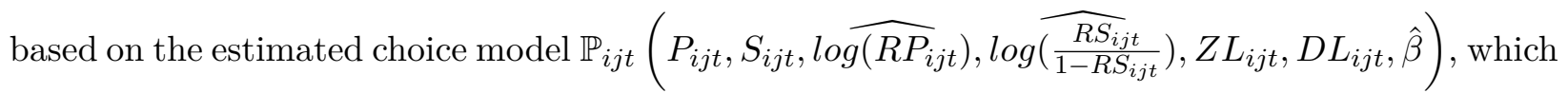
involves loss aversion in both price and sales. ${ }^{12}$

\footnotetext{
${ }^{12}$ The estimates are reported in Column (C) in Table 3 for this choice model.
} 
We initialize the exponential smoothing/memory updating of the past prices and seats sold (see equations (13) and (14)) by using the list ticket prices, and the average number of seats sold as a fraction of capacity at the point of initialization (0.6). Our results continue to hold on perturbation of the initial parameters.

We make two observations related to prices and loss aversion. First, under price loss aversion, consistent or monotone prices are preferred and usually recommended relative to a price sequence with many up-down jumps (see Popescu and Wu 2007). For instance, a consumer would suffer a lower loss on the price path $(\$ 12, \$ 12, \$ 12)$ than on the price path $(\$ 10, \$ 15, \$ 10)$. However, it is unclear how such consistent pricing would work in practical settings because (i) reference levels are not observable and (ii) it appears that consumers are using multi-attribute reference points while making their choices on multiple alternatives.

Second, as the average capacity filled in the data is typically low across seating zones (ranging from 0.56 to 0.79 ), there are many empty seats for which tickets remain to be sold. Hence, a pricing scheme with consistent increases from one performance to the next, leads to lower utility (due to a combination of factors including loss aversion and likely low reference thresholds on prices). Moreover, increasing monotone price path, even if it improves revenues, would lead to lower sales - which might affect future purchases, due to loss aversion in seats sold.

Based on the two observations above, we study two policies. As a benchmark policy (policy $\mathcal{A}$ ), we consider the static policy of announcing the list price for each performance ahead of the season, and staying at the same price throughout the season for all performances. Next, we consider a discount policy that decreases prices for future performances (policy $\mathcal{B}$ ). For instance, in the holdout, we set the prices at list price for the first two performances and at (list price - discount) for the remaining performances. ${ }^{13}$

Policies Based on Price-Referencing Only. In Table 5, we report the revenues for each seating zone (and the total revenue) for all policies. The benchmark policy and three variants of discount policy (policy $\mathcal{B}$ ) are considered. For the three policies, the prices are dropped by $\$ 3.00$, $\$ 4.00$, and $\$ 5.00$ for performances $\{3, \ldots, 7\}$. The averages are calculated by repeated sampling from a sequence of 1000 independent runs.

\footnotetext{
${ }^{13}$ We also tested gradual price decreases, which are omitted for brevity. They lead to similar qualitative insights.
} 


\begin{tabular}{ccccc} 
Zones & $\begin{array}{c}\text { List Prices }(\$) \\
(\text { Benchmark) }\end{array}$ & $\begin{array}{c}\text { Decrease by } \$ 3.00 \\
\text { for Performances } \\
3,4,5,6,7(\$)\end{array}$ & $\begin{array}{c}\text { Decrease by } \$ 4.00 \\
\text { for Performances } \\
3,4,5,6,7(\$)\end{array}$ & $\begin{array}{c}\text { Decrease by } \$ 5.00 \\
\text { for Performances } \\
3,4,5,6,7(\$)\end{array}$ \\
\hline 1 & $20,373.74$ & $17,010.86$ & $16,084.78$ & $14,600.11$ \\
2 & $33,936.19$ & $31,747.87$ & $30,395.79$ & $28,392.45$ \\
3 & $7,765.05$ & $8,194.55$ & $8,453.49$ & $8,064.21$ \\
4 & $9,818.93$ & $10,365.36$ & $10,219.04$ & $10,259.26$ \\
5 & $8,614.20$ & $9,815.14$ & $9,794.38$ & $9,809.04$ \\
6 & $1,495.17$ & $1,939.15$ & $2,080.63$ & $2,180.64$ \\
7 & 633.72 & 991.38 & $1,127.26$ & $1,389.51$ \\
8 & 389.88 & 925.92 & $1,325.21$ & $2,006.95$ \\
\hline Total & $83,026.86$ & $80,990.20$ & $79,480.57$ & $76,702.16$ \\
\hline
\end{tabular}

Table 5: Revenues obtained from pricing experiments which do not consider sales reference positions relative to actual sales.

In Table 5, policies with decreasing prices perform worse than the constant pricing strategy by about $2.5 \%$ ( $\$ 80,990$ vs. $\$ 83,026)$. Furthermore, revenues continue to decrease even further as we increase the size of the discount from $\$ 3.00$ to $\$ 4.00$ and $\$ 5.00$. This result is surprising in the context of theoretical literature showing such monotone policies perform better when the initial references prices are high (Popescu and $\mathrm{Wu} 2007)$. Note that our initialization starts with list prices, hence high reference levels. Despite this similarity, the monotone decreasing scheme does to not perform well.

The discounting schemes underperform because the following two features are ignored in the above policy in which the focus is only on price loss aversion: (i) the inter-dependencies between price and seat sales, and (ii) the resultant sales loss aversion effects. As our data supports, the number of seats sold as a fraction of capacity, which is observed prior to purchase, is a key driver of consumer decisions. Hence, policies need to take that information into consideration.

In fact, seats sold as a fraction of capacity are disparate between different seating zones in the validation data set. The most expensive zones (1, 2, and 3) had higher capacity filled (>60\%) compared to other zones (4 to 8 - lower than $60 \%$ ).

It is initially surprising that higher-priced zones have more seats being sold (as a fraction of capacity). Nevertheless, reference dependence on seats sold possibly creates positive externalities that drive more ticket sales in those sections (all else being equal). Similarly, fewer tickets sold in less expensive zones may be tempering further future sales. Hence it is relevant that prices be re-adjusted in consideration of both past prices and past seat sales (i.e., reference-dependence). 
Policies Based on Price and Sales Referencing. We now consider a sales based pricing policy that is identical to the decreasing policy we considered in Table 5, except that the discount in ticket prices is applied only in select zones. In our data, we apply the price discount to only zones 1,2 and 3 (which are the zones with higher prices).

In Table 6, we summarize the revenues obtained by the policies. For comparison, the revenues from the benchmark list price policy (policy $\mathcal{A}$ ) are also presented. Note that the performance of the sales reference based policies perform better than both benchmark policy (policy $\mathcal{A}$ ) and other previous policies (policy $\mathcal{B})$. In particular, the sales based discount policy improves significantly on the constant list price-based policy. A $\$ 5$ discount on ticket prices provides an improvement in revenues to $\$ 85,134$ compared to the benchmark policy at $\$ 83,026.86$. We also observe that this strategy continues to be favorable when we change the price decrease from $\$ 5.00$ to $\$ 3.00$.

\begin{tabular}{ccccc} 
Zones & $\begin{array}{c}\text { List Prices }(\$) \\
(\text { Benchmark) }\end{array}$ & $\begin{array}{c}\text { Decrease by } \$ 3.00 \\
\text { for Zones } 1,2,3 \\
\text { of Performances } \\
3,4,5,6,7(\$)\end{array}$ & $\begin{array}{c}\text { Decrease by } \$ 4.00 \\
\text { for Zones } 1,2,3 \\
\text { of Performances } \\
3,4,5,6,7(\$)\end{array}$ & $\begin{array}{c}\text { Decrease by } \$ 5.00 \\
\text { for Zones } 1,2,3 \\
\text { of Performances }\end{array}$ \\
\hline 1 & $20,373.74$ & $20,064.29$ & $19,976.74$ & $19,6,6,7(\$)$ \\
\hline 2 & $33,936.19$ & $35,742.85$ & $36,974.07$ & $37,397.79$ \\
3 & $7,765.05$ & $9,683.73$ & $10,361.05$ & $10,973.88$ \\
4 & $9,818.93$ & $8,620.80$ & $8,051.40$ & $7,885.78$ \\
5 & $8,614.20$ & $7,891.30$ & $7,199.23$ & $7,132.74$ \\
6 & $1,495.17$ & $1,339.68$ & $1,157.87$ & $1,218.14$ \\
7 & 633.72 & 594.05 & 567.77 & 538.71 \\
8 & 389.88 & 332.84 & 322.63 & 302.34 \\
\hline Total & $83,026.86$ & $84,269.52$ & $84,610.75$ & $85,134.50$ \\
\hline
\end{tabular}

Table 6: Revenues obtained from pricing experiments which consider both pice and sales reference effects.

Finally, we compare the corresponding columns in Table 5 and 6 . Note that the only difference is that the discount is applied in a subset of zones in Table 6. Nevertheless, the revenues improve significantly. The distinction between the two policies is that sales information is taken into account.

In Table 6, we apply the discounts in high-priced zones and surprisingly to zones with high capacity filled, instead of trying to improve sales by discounting in low-filled zones. Without multiattribute reference dependence, such an action is not intuitive. 
Why does the zone-sales specific policy perform better? We explain using the two facets of our research, (i) multi-attribute reference dependence and (ii) loss aversion on both prices and sales. A price discount leads to a gain in utility, which increases the probability of choosing the zone. There are two possible outcome effects depending on zone sales (compared to reference levels). Zones with poor sales: If the actual sales in the zone is less than sales reference, a small increase in utility (due to price gain) is subsumed by the larger pre-existent loss effect. Furthermore, due to discounting, the sales reference is gradually revised upwards. Hence, the sales observations continue to remain below the reference level $(\mathrm{SLOSS}>0, \mathrm{SGAIN}=0)$. No further ticket purchases may occur, despite the discount. If the seat loss aversion is significantly large, there may be no additional ticket sales.

Zones with good sales: On the other hand, if the actual sales in the zone is higher than the reference level on seats sold, the increase in SGAIN, however small, adds to PGAIN. This further improves reference-dependent utility, and consumers choose that zone with a higher probability, thus increasing ticket sales further in that zone. Surely, the reference levels are also updated upwards exponentially, but the reference effects will be gradual in their growth as memories are long (i.e., $\theta=0.8)$. It takes multiple periods before the reference level can exceed the actual sales that are also improving (on average).

To summarize, in the light of multi-attribute reference effects, the discount-related gains are achieved in those zones with higher ticket sales (compared to sales reference points). In practice, it may be easier to improve occupancy levels through other means, such as upgrading customers to specific zones or restricting zone capacities. While upgrading is relatively uncommon in this industry, closing of empty zones (decreasing capacity, improving occupancy) have been observed in practice in stadium settings.

The Effect of Event Popularity. The zone-sales based discounting policy is particularly relevant to concerts that have poor or lukewarm overall sales (using past concert sales as reference benchmarks to judge event popularity). It appears that consumers react particularly strongly to sales loss in concerts with lukewarm attendance. In our data, we found the effect for lower-thanmedian attendance. Consider two zones with $65 \%$ and $35 \%$ occupancy, both with $60 \%$ reference level. Discounting further in the $35 \%$ occupied zone amplifies the price gain and sales loss in utili- 
ties. However, price gain may not compensate for the sales loss due to stronger sales loss aversion. So, no additional purchases may occur despite the discounting action. Discounting tickets in the $65 \%$ occupied zone creates price-gain but no sales-loss in utilities. Thus, the discount would lead to improved utility and improved ticket sales, which in turn makes the concert slightly more popular, and drives the seat loss aversion down further (which could make further discounting in zones also easier).

On the other hand, for popular concerts, loss aversion on sales is dampened even as referencedependence persists. For concerts with high sales, customers react with lower loss aversion, if they observe seat sales lower than their reference level. It could be that empty seats are relatively rare occurrences in such cases (e.g. observed occupancy of $95 \%$ vs. the reference level of $97 \%$ ). Overall event popularity to a certain extent, may also obviate the need for deep discounting.

\section{Conclusions}

In this paper, we empirically explore the role of reference effects and loss aversion on price and observed sales (as a fraction of the capacity) in consumer decisions, and used counterfactual experiments to explore policy recommendations and to show how sales may play a significant role in pricing decisions of a theater.

To summarize, we make the following contributions: (i) We provide empirical evidence for multi-attribute reference dependence and loss aversion. We find that consumers use their past observations to develop multi-attribute reference levels on prices and capacity sold. (ii) Our application for reference dependence is novel and relevant. Most previous literature dealt with consumer goods and commodity products (as against experience goods where reference effects are likely important). (iii) Our reference attribute (sales level - a key operational attribute) is endogenous. We are unaware of any other paper using multi-attribute and endogenous reference levels. (iv) We provide a structural model approach to use repeated purchase data to infer unobservable reference levels. The reference-level findings are robust to model variations, such as event popularity, visit frequency and memory updating behavior. (v) In particular, we find that while loss aversion in sales may dampen for popular events, the reference-dependent choice behavior is persistent. (vi) We finally provide some discount insights. We show how a simple monotone policy may be less 
efficient and discounting should account for zone-level sales. It may be worthy to promote sales in "busy" zones, which may improve future revenues due to reference dependence.

Like many studies, our study has its limitations on data and modeling, which influence policy findings. Our discounting recommendations are based on our choice model and internal reference levels. Hence, if loss aversion is evident in data, we believe that further pricing/seat allocation experimentation would help in devising discount schemes that integrate reference-dependent behavior.

Our choice model assumes homogeneity in response to other marketing mix variables. As suggested by Hardie et al. (1993) in another context, loss aversion and reference effects captured by multi-attribute constructs (the price and observe sales variables in our model) might also be capturing underlying heterogeneity in household response to other marketing mix variables. To maintain the research focus, our model assumes homogeneity for loss aversion coefficients for both price and sales attributes across customers. Bell and Lattin (2000) shows that estimated coefficients for loss aversion may decrease when such heterogeneity is modeled explicitly using finite mixture models. Thus, it would be interesting to allow these coefficients to vary across consumers as a natural extension. Our model also ignores the effect of competition due to the nature of data from a unique organization. However, in many settings, the competitive reference effects can be strong. For example, consumers could use price of the competitive product as a reference.

Our model can be directly applied to settings with a season with multiple performances at a theater/musical venue, or a season with multiple games at a sports venue, if we appropriately integrate covariates that are specific to those settings. We believe that the primary structure can be translated to most settings with minimal variations. Finally, we explore a parametric model. Non-parametric characterization of reference effects remains a challenging future research direction.

An open theoretical question is the characterization of optimal pricing policy when there is loss aversion not only in prices, but also on sales. A relevant question of practical interest in theaters and stadiums is to what extent an organization should share its seat availability information. For many venues, seat maps are available - some at the zone level and some at the specific seat level. The specificity of information provision is an interesting direction for future research.

Our study of unobservable reference effects on price and capacity sold provides evidence that multiple reference levels can be jointly formed in practice. There is an underlying need to explore 
how the endogenous interaction between the reference effects could be combined into a final operations or marketing decision. Thus, there are analytical and empirical research opportunities in markets with similar structure such as prices and waiting times in services. Another potential setting for further exploration on multi-attribute references can be online product/seller reviews and prices of products on e-commerce websites.

\section{References}

Aflaki, S., I. Popescu. 2014. Managing retention in service relationships. Management Science 60(2) 415-433.

Aggarwal, P. 2004. The effects of brand relationship norms on consumer attitudes and behavior. Journal of Consumer Research 31(1) 87-101.

Allen, E. J., P. M. Dechow, D. G. Pope, G. Wu. 2013. Reference-dependent preferences: Evidence from marathon runners. Working Paper, University of Chicago, Chicago, IL.

Amaldoss, W., S. Jain. 2005a. Conspicuous consumption and sophisticated thinking. Management Science 51(10) 1449-1466.

Amaldoss, W., S. Jain. 2005b. Pricing of conspicuous goods: A competitive analysis of social effects. Journal of Marketing Research 42(1) 30-42.

Barseghyan, L., J. Prince, J. C. Teitelbaum. 2011. Are risk preference stable across contexts? Evidence from insurance data. American Economic Review 101(2) 591-631.

Becker, G. 1991. A note on restaurant pricing and other examples of social influence on price. Journal of Political Economy 99(5) 1109-1116.

Bell, D. R., J. M. Lattin. 2000. Looking for loss aversion in scanner panel data: The confounding effect of price response heterogeneity. Marketing Science 19(2) 185-200.

Bikhchandani, S., D. Hirshleifer, I. Welch. 1992. A theory of fads, fashion, customer, and cultural change as informational cascades. Journal of Political Economy 100(5) 992-1026. 
Briesch, R. A., L. Krishnamurthi, T. Mazumdar, S. P. Raj. 1997. A comparative analysis of reference price models. Journal of Consumer Research 24(2) 202-214.

Camerer, C., L. Babcock, G. Loewenstein, R. Thaler. 1997. Labor supply of New York City cabdrivers: One day at a time. Quarterly Journal of Economics 112(2) 407-441.

Cialdini, R. B. 2007. Influence: The Psychology of Persuasion. Rev. ed.; 1st collins business essentials ed. Collins, New York.

Cialdini, R. B., N. J. Goldstein. 2004. Social influence: Compliance and conformity. Annual Review of Psycology 55 591-621.

Debo, L. G., C. Parlour, U. Rajan. 2012. Signaling quality via queues. Management Science 58(5) 876-891.

DeGraba, P. 1995. Buying frenzies and seller-induced excess demand. RAND Journal of Economics 26(2) 331-342.

DellaVigna, S. 2009. Psychology and economics: Evidence from the field. Journal of Economic Literature $\mathbf{4 7}(2) 315-372$.

Fader, P. S., J. M. Lattin, J. D. C. Little. 1992. Estimating nonlinear parameters in the multinomial logit model. Marketing Science 11(4) 372-385.

Fibich, G., A. Gavious, O. Lowengart. 2003. Explicit solutions of optimization models and differential games with nonsmooth (asymmetric) reference-price effects. Operations Research 51(5) $721-734$.

Genesove, D., C. Mayer. 2001. Loss aversion and seller behavior: Evidence from the housing market. Quarterly Journal of Economics 116(4) 1233-1260.

Greene, W. H. 2011. Systems of equations. Econometric Analysis, 7th ed. Prentice Hall, Upper Saddle River, NJ.

Guadagni, P. M., J. D. C. Little. 1983. A logit model of brand choice calibrated on scanner data. Marketing Science 2(3) 203-238. 
Gustafsson, A., M. D. Johnson, I. Ross. 2005. The effects of customer satisfaction, relationship commitment dimensions, and triggers on customer retention. Journal of Marketing 69(4) 210218.

Hardie, B. G. S, E. J. Johnson, P. S. Fader. 1993. Modeling loss aversion and reference dependence effects on brand choice. Marketing Science 12(4) 378-394.

Henningsen, A., O. Toomet. 2011. maxlik: A package for maximum likelihood estimation in R. Computational Statistics 26(3) 443-458.

Hossain, T., J. A. List. 2012. The behavioralist visits the factory: Increasing productivity using simple framing manipulations. Management Science 58(12) 2151-2167.

Johnson, M. D., A. Herrmann, F. Huber. 2006. The evolution of loyalty intentions. Journal of Marketing 70(2) 122-132.

Kahneman, D., A. Tversky. 1979. Prospect theory: An analysis of decision under risk. Econometrica $47(2)$ 263-291.

Kalwani, M. U., C. H. Yim, H. J. Rinne, Y. Sugita. 1990. A price expectation model of customer brand choice. Journal of Marketing Research 27(3) 251-262.

Kalyanaram, G., J. D. C. Little. 1994. An empirical analysis of latitude of price acceptance in consumer packaged goods. Journal of Consumer Research 21(3) 408-418.

Kalyanaram, G., R. S. Winer. 1995. Empirical generalizations from reference price research. Marketing Science 14(3-supplement) G161-G169.

Katz, M., C. Shapiro. 1985. Network externalities, competition, and compatibility. American Economic Review 75(3) 424-440.

Kohavi, R. 1995. A study of cross-validation and bootstrap for accuracy estimation and model selection. IJCAI'95 Proc. 14th Internat. Joint Conf. Artificial Intelligence, vol. 2. Morgan Kaufmann Publishers Inc., San Francisco, CA, 1137-1143.

Kopalle, P. K., A. G. Rao, J. L. Assuncao. 1996. Asymmetric reference price effects and dynamic pricing policies. Marketing Science 15(1) 60-85. 
Köszegi, B., M. Rabin. 2006. A model of reference-dependent preferences. Quarterly Journal of Economics 121(4) 1133-1165.

Krishnamurthi, L., T. Mazumdar, S. P. Raj. 1992. Asymmetric response to price in consumer brand choice and purchase quantity decisions. Journal of Consumer Research 19(3) 387-400.

Lattin, J. M., R. E. Bucklin. 1989. Reference effects of price and promotion on brand choice behavior. Journal of Marketing Research 26(3) 299-310.

Leslie, P. 2004. Price discrimination in Broadway theater. RAND Journal of Economics 35(3) $520-541$.

Liu, Q., S. Shum. 2013. Pricing and capacity rationing with customer disappointment aversion. Production and Operations Management 22(5) 1269-1286.

Mayhew, G. E., R. S. Winer. 1992. An empirical analysis of internal and external reference prices using scanner data. Journal of Consumer Research 19(1) 62-70.

McFadden, D. 1974. Conditional logit analysis of qualitative choice behavior. P. Zarembka, ed., Frontiers in Econometrics. Academic Press, New York.

Nasiry, J., I. Popescu. 2011. Dynamic pricing with loss-averse consumers and peak-end anchoring. Operations Research 59(6) 1361-1368.

Nodder, C. 2013. Pride. Evil by Design: Interaction Design to Lead Us into Temptation. John Wiley \& Sons, Inc., Indianapolis, IN.

Pope, D. G., M. E. Schweitzer. 2011. Is Tiger Woods loss averse? Persistent bias in the face of experience, competition, and high stakes. American Economic Review 101(1) 129-157.

Popescu, I., Y. Wu. 2007. Dynamic pricing strategies with reference effects. Operations Research 55(3) 413-429.

Post, T., M. J. van den Assem, G. Baltussen, R. H. Thaler. 2008. Deal or no deal? Decision making under risk in a large-payoff game show. Americna Economic Review 98(1) 38-71.

Roels, G., X. Su. 2014. Optimal design of social comparison effects: Setting reference groups and reference points. Management Science 60(3) 606-627. 
Rosen, S., A. M. Rosenfield. 1997. Ticket pricing. Journal of Law and Economics 40(2) 351-376.

Talluri, K. T., G. J. van Ryzin. 2004. The Theory and Practice of Revenue Management. Kluwer Academic Publishers, Norwell, MA.

Tanner, R. 2014. Seeking safety in numbers: Do consumers think and choose differently in crowded stores? Forbes (February 4). http://www.forbes.com/sites/onmarketing/2014/02/04/seekingsafety-in-numbers-do-consumers-think-and-choose-differently-in-crowded-stores/.

Tversky, A., D. Kahneman. 1991. Loss aversion in riskless choice: A reference dependent model. Quarterly Journal of Economics 106(4) 1039-1061.

Veeraraghavan, S., L. Debo. 2009. Joining longer queues: Information externalities in queue choice. Manufacturing and Service Operations Management 11(4) 543-562.

Veeraraghavan, S., R. Vaidyanathan. 2012. Measuring seat value in stadiums and theaters. Production and Operations Management 21(1) 49-68.

Winer, R. S. 1986. A reference price model of brand choice for frequently purchased products. Journal of Consumer Research 13(2) 250-256.

Yang, L., F. de Vericourt, P. Sun. 2014a. Time-based competition with benchmark effects. Manufacturing and Service Operations Management 16(1) 119-132.

Yang, L., P. Guo, Y. Wang. 2014b. Service pricing with loss averse customers. Working Paper, Tsinghua University, China.

Zaki, J. 2013. Crowds versus company: When are we drawn to groups? Scientific American (blog)(November 21). http://blogs.scientificamerican.com/moral-universe/2013/11/21/crowdsversus-company/.

Zellner, A., J. Kmenta, J. Drèze. 1966. Specification and estimation of cobb-douglas production function models. Econometrica 34(4) 784-795. 